\title{
PENENTUAN PRIORITAS JENIS AGROINDUSTRI KELAPA DI KABUPATEN HALMAHERA BARAT
}

\author{
Relanti Irene Sopacua1), Anna Fariyanti2), dan Burhanuddin ${ }^{3)}$ \\ 1)Sekolah Tinggi Pertanian Kewirausahaan Banau Halmahera Barat \\ Jl. Trans Goa Sahu Timur Halmahera Barat, Indonesia \\ 2,3)Departemen Agribisnis, Fakultas Ekonomi dan Manajemen, Institut Pertanian Bogor \\ Jl. Kamper Wing 4 Level 5 Kampus IPB Dramaga, Indonesia \\ 1)e-mail: relantiirenesopacua@gmail.com
}

(Diterima 23 Maret 2019 / Disetujui 22 April 2019)

\begin{abstract}
The main source offarmer households in West Halmahera is coconut plantations. Coconut fruit is produced, some are sold in the form of whole fruit, some are processed into copra. For this agro-industry development effort to work effectively, it is necessary to determine the type of coconut agroindustry that will be developed by considering the factors that increase, the efforts of the businesses involved and the objectives of each of the agro-industries. The purpose of this study was to determine the priorities of coconut agroindustry that had to be developed in West Halmahera Region. The data were analyzed using the Process Hierarchy Analysis (AHP) approach and internal-external factor. The results showed that the virgin coconut oil (VCO) agro-industry had the highest priority in the development of coconut agro-industry in West Halmahera. By the development of this agro-industry, business actors will gain added value, affect the increase in income, and will open new jobs in the rural area. The important factors that have influenced the development of agro-industry were human resources (HR) and asset. Furthermore, each actor involved has a firm role and linkage to each of the determinants of agro-industry business development. Farmers have the main role (37\%) on the availability of raw materials, farmer groups have strong correlation (42\%) to human resources, the government plays an important role (42\%) in infrastructure development, and academics have an enormous contribution (34\%) in providing technology for the development of agroindustry. Overall, the most important actors in the development of coconut agro-industry in West Halmahera are farmer groups. The Strategy applied to agro-industry virgin coconut oil (VCO) at West Halmahera Region is intensive: market penetration, market development and product development.
\end{abstract}

Keywords: agroindustry, coconut, development strategy, VCO

\begin{abstract}
ABSTRAK
Sumber utama pendapatan rumah tangga petani di Halmahera Barat adalah dari perkebunan kelapa. Buah kelapa yang dihasilkan, ada yang dijual dalam bentuk buah utuh, ada pula yang diolah menjadi kopra. Agar usaha pengembangan agroindustri ini dapat berjalan dengan efektif maka perlu ditentukan prioritas jenis agroindustri kelapa yang akan dikembangkan dengan mempertimbangkan faktor yang mempengaruhi, pelaku usaha yang terlibat serta tujuan dari masing-masing pelaku agroindustri. Tujuan dari penelitian ini adalah menentukan prioritas jenis agroindustri dan strategi pengembangan VCO di Kabupaten Halmahera Barat. Data dianalisis menggunakan pendekatan Analisis Hierarki Proses (AHP) dan faktor internal eksternal menggunakan matriks IE. Hasil penelitian menunjukkan bahwa agroindustri minyak kelapa murni (VCO) memiliki prioritas tertinggi dalam pengembangan agroindustri kelapa di Halmahera Barat. Dengan berkembanganya agroindustri ini, pelaku usaha akan mendapatkan nilai tambah, mempengaruhi peningkatan pendapatan, dan akan membuka lapangan kerja baru di daerah pedesaan. Faktor-faktor penting yang mempengaruhi perkembangan agroindustri adalah sumber daya manusia (SDM) dan modal. Selanjutnya, Aktor yang terpenting dalam pengembangan agroindustri kelapa adalah kelompok tani. Aktor Petani memiliki peran yang sangat kuat (37\%) terhadap faktor ketersediaan bahan baku, sedangkan kelompok tani memiliki peran yang sangan kuat terhadap faktor SDM (42\%). Pada faktor infrastruktur, pemerintah memiliki perang yang sangat penting (42\%) dan aktor akademisi memiliki peran (34\%) dalam menyediakan teknologi bagi pengembangan usaha agroindusti di Kabupaten Halamahera Barat. Strategi yang diterapkan pada VCO di Kabupaten Halmahera Barat adalah Strategi intensif: penetrasian pasar, pengembangan pasar dan pengembangan produk.
\end{abstract}

Kata Kunci: agroindustry, kelapa, strategi pengembangan, VCO 


\section{PENDAHULUAN}

Sektor pertanian merupakan salah satu sektor utama dari perekonomian suatu negara. Kemajuan sektor pertanian dapat dilihat dari sejauhmana kemajuan pembangunan dalam memperbesar produksi pertanian sekaligus meningkatkan pendapatan dari usaha yang dijalankan oleh petani. Secara umum peranan sektor pertanian dalam perekonomian Indonesia adalah: (1) pembentuk Produk Domestik Bruto (PDB), (2) sumber penghasil devisa, (3) penyedia pangan penduduk dan bahan baku industri, (4) sektor yang dapat menuntaskan masalah kemiskinan, (5) penyedia lapangan kerja, (6) salah satu sumber peningkatan pendapatan masyarakat, dan (7) sumber pemantapan ketahanan pangan nasional (Kuncoro, 2012).

Sebagai sektor yang menjadi sumber peningkatan pendapatan masyarakat, maka perlu adanya upaya untuk mencapai tujuan tersebut. Upaya peningkatan kesejahteraan masyarakat dapat dilakukan dengan melakukan pengolahan secara optimal produktivitas dari sumber daya alam yang dimiliki di berbagai sektor sehingga berimplikasi pada kesejahteraan masyarakat. Salah satu subsektor pertanian yang dapat dikembangkan sebagai agroindustri adalah subsektor perkebunan.

Kelapa merupakan salah satu komoditas strategis dari sub sektor perkebunan yaitu sebagai sumber pendapatan, sumber utama minyak dalam negeri, sumber devisa, sumber bahan baku industri dan sebagai penyedia lapangan kerja (Pathiraja et al., 2015). Beberapa jenis produk kelapa yang tidak dapat digantikan oleh kelapa sawit antara lain santan, gula, air kelapa segar, lidi, janur dan daging kelapa. Selain itu masih ada lagi produk yang dihasilkan dari tanaman kelapa seperti arang aktif, sabut dan industri kerajinan tangan. Bahkan limbah kelapa pun masih dapat digunakan sebagai pakan ternak (Budiarto, 2010). Kelapa merupakan salah satu komoditas unggulan Kabupaten Halmahera Barat. Tahun 2016 luas lahan kelapa mencapai $31.644 \mathrm{Ha}$.

Sumber utama pendapatan rumah tangga petani di Halmahera Barat adalah dari perkebunan kelapa. Buah kelapa yang dihasilkan, ada yang dijual dalam bentuk buah utuh, ada pula yang diolah menjadi kopra. Berdasarkan data Dinas
Perindustrian dan Perdagangan (DISPERINDAG) tahun 2016, selain kopra, telah dikembangkan beberapa produk turunan dari kelapa diantaranya minyak, minuman segar dari air kelapa, kerajinan batok kelapa dan virgin coconut oil (VCO). Produk tersebut tidak diproduksi secara terus-menerus, tetapi hanya ketika ada permintaan atau pameran sehingga berakibat pada rendahnya nilai tambah yang diterima oleh petani. Penanganan pascapanen yang belum optimal ini, disebabkan oleh beberapa masalah seperti kelangkaan tenaga kerja terampil, harga rendah \& berfluktuasi (Suharto, 2018), produktivitas yang menurun (Krishnakumar et al., 2013), kurangnya informasi di kalangan petani, dan keterbatasan produksi berbagai jenis produk olahan kelapa (Muyengi et al., 2015).

Ketersediaan sumberdaya yang memadai hendaknya dapat dimanfaatkan dengan sebesarbesarnya untuk kesejahteraan rakyat (Lay dan Pasang, 2012). Karena industri kelapa mendukung proporsi yang sangat besar dari populasi pedesaan (petani), maka pertumbuhan dalam pendapatan sektor pertanian akan membantu meningkatkan kesejahteraan petani secara langsung dan juga cenderung menjadi pendorong penting pembangunan ekonomi daerah (Henderson et al., 2006). Menurut Ulrich dan Eppinger (2001) pengembangan dikatakan sukses apabila produk yang dihasilkan memperoleh laba. Hal ini selaras dengan salah satu misi pemerintah Kabupaten Halmahera Barat 2016-2021 yakni meningkatkan perekonomian daerah, daya saing industri pertanian, perikanan, pariwisata dan budaya dengan pendidikan ekonomi kerakyatan. Peningkatan perekonomian dapat dilakukan dengan pengembangan sumberdaya manusia dan peningkatan industri kecil yang berbasis pada potensi hasil produk unggulan daerah. Salah satunya adalah dengan mengembangkan diversifikasi produk agroindustri kelapa yang merupakan komoditas unggulan Halmahera Barat.

Diversifikasi tidak hanya meningkatkan ekspor, menarik pendapatan tambahan tetapi juga menghapus impor produk kelapa atau pengganti. Diversifikasi juga dapat menjamin keberlangsungan usaha secara terus menerus. (Suharto, 2018). Agar pengembangan diversifikasi produk agroindustri kelapa ini berjalan dengan efektif 
maka perlu dilakukan kajian dan analisis mengenai alternatif agroindustri potensial yang layak dikembangkan dengan mempertimbangkan faktor yang mempengaruhi, dan aktor yang terlibat. Tujuan penelitian ini adalah menentukan jenis agroindustri kelapa, selain itu perlu dibuat sebuah strategi untuk pengembangan agroindustri kelapa terpilih, sehingga melalui pengembangan ini diharapkan dapat memberikan kontribusi dalam meningkatkan pendapatan petani dan pelaku agroindustri kelapa.

\section{METODE}

Penelitian ini dilaksanakan di Kabupaten Halmahera Barat pada bulan April - September 2017. Penentuan lokasi ini dilakukan secara sengaja (purposive) dengan mempertimbangkan bahwa Kabupaten Halmahera Barat memiliki agroindustri yang sudah dikembangkan.

\section{JENIS DAN SUMBER DATA}

Jenis data yang digunakan pada penelitian ini adalah data primer dan data sekunder. Data primer diperoleh melalui observasi dan wawancara langsung menggunakan kuesioner, untuk menentukan jenis agroindustri kelapa dilakukan wawancara terhadap 9 responden diantaranya: Akademisi, Dinas Perindustrian dan Koperasi Bidang Industri, Dinas Pertanian Bidang Perkebunan dan pelaku usaha agroindustri kelapa. Sedangkan untuk strategi pengembangan dilakukan wawancara terhadap 5 responden kunci. Data sekunder diperoleh melalui hasil telaah literatur/ dokumen yang relevan dan data yang berasal dari instansi/lembaga yang terkait (Dinas Pertanian, Perindustrian, Badan Pusat Statistik Halmahera Barat).

\section{ANALISIS DATA}

Tujuan penelitian pertama menentukan prioritas jenis produk agroindustri kelapa, analisis data menggunakan metode Analytical Hierarchy Process (AHP) yang dikembangkan oleh Saaty (1990), dengan bantuan Expert Choice. Metode ini dipilih karena dapat digunakan untuk mendapatkan skala prioritas dengan cara menstrukturkan masalah dalam bentuk hirarki dan memasukkan unsur-unsur pertimbangan para pakar (Marimin dan Maghfiroh, 2010).

Prinsip kerja AHP adalah menyederhanakan suatu persoalan kompleks dan tidak terstruktur serta bersifat strategis dan dinamis melalui upaya penantaan rangkaian variabelnya dalam suatu hirarki. Beberapa prinsip hirarki yang harus dipahami adalah:

1. Dekomposisi, yaitu penguraian masalah menjadi unsur-unsurnya bahkan setiap unsur juga diurai hingga tidak mungkin dilakukan pemecahan lagi sehingga didapat beberapa tingkat hiraarki dari masalah tersebut.

2. Penilaian secara komparatif, yaitu nilai tingkat kepentingan dua elemen pada satu tingkat tertentu dalam kaitannya dengan tingkat diatasnya. Penilaian dengan teknik komparasi berpasangan antar elemen dalam suatu hirarki dilakukan dengan memberi bobot numerik. Skala komparasi yang efektif adalah 1 sampai dengan 9 (Saaty, 2008). Skala dasar tersebut direpresentasikan pada Tabel 2. Penilaian ini akan mempengaruhi prioritas elemen-elemen. Hasil penilaian disajikan dalam bentuk matriks pairwise comparison.

3. Sintesis prioritas, yaitu proses untuk mencari glopal priority elemen-elemen menurut kepentingan relatif melalui prosedur sintesis diantara local priority, yaitu prioritas disuatu tingkat hirarki yang dinamakan proirity setting. Terdapat beberapa cara untuk mencari vektor prioritas dari matriks pairwise comparision. Pendekatan pada konsistensi menyebabkan digunakannya rumus eigen value. Adapun rumus yang digunakan untuk para pengambil keputusan menggunakan software AHP:

$$
\begin{gathered}
V E_{1}(\text { Vektor Eigen })=\sqrt[n]{\sum_{j=1, i=1,2 \ldots n}^{n} a_{i}} \\
V_{p i}(\text { Vektor Prioritas })=\frac{V E_{1}}{n} \\
\sum_{i=1} V E \\
V A(\text { Vektor Antara })=a_{i j} x V P \\
V B \text { (Nilai Eigen })=\frac{V A}{V P} \\
\pi_{\max }\left(\text { Nilai Eigen } \text { max }_{\text {max }}\right)=\frac{\sum V B}{n}
\end{gathered}
$$




$$
\begin{gathered}
\left.C I(\text { Index Konsistensi })=\pi_{\max }-n\right) /(n-1) \\
C R(\text { Rasio Konsistensi })=\left(\frac{C I}{R I}\right)
\end{gathered}
$$

Tabel 1. Random Konsistensi Indeks

\begin{tabular}{cccccc}
\hline $\mathbf{N}$ & $\mathbf{R I}$ & $\mathbf{N}$ & $\mathbf{R I}$ & $\mathbf{N}$ & $\mathbf{R I}$ \\
\hline 1 & 0,00 & 6 & 1,24 & 11 & 1,51 \\
2 & 0,00 & 7 & 1,32 & 12 & 1,48 \\
3 & 0,58 & 8 & 1,41 & 13 & 1,56 \\
4 & 0,90 & 9 & 1,45 & 14 & 1,57 \\
5 & 1,12 & 10 & 1,49 & 15 & 1,49 \\
\hline \multicolumn{5}{l}{ Sumber: Marimin dan Maghfiroh (2014) }
\end{tabular}

4. Logical consistency, yaitu konsistensi pendapat dalam matriks perbandingan berpasangan dalam suatu masalah. Konsistensi sampai batas tertentu dalam menetapkan prioritas sangat diperlukan untuk memperoleh hasilhasil yang baik. AHP mengukur konsistensi menyeluruh dari berbagai pertimbangan melalui suatu rasio konsistensi. Nilai rasio konsistensi harus 10 persen atau kurang. Jika lebih dari 10 persen maka penilaiannya masih acak dan perlu diperbaiki.

Tabel 2. Nilai dan Definisi Skala Perbandingan pada AHP

\begin{tabular}{cl}
\hline Nilai & \multicolumn{1}{c}{ Keterangan } \\
\hline 1 & Kriteria/alternatif A sama penting \\
& dengan kriteria/alternatif B \\
3 & A sedikit lebih penting dari B \\
5 & A jelas lebih penting dari B \\
7 & A sangat jelas lebih penting dari B \\
9 & A mutlak lebih penting dari B \\
$2,4,6,8$ & Apabila ragu-ragu antara nilai yang \\
& berdekatan \\
\hline Keterangan: & Nilai perbandingan A dengan B adalah satu \\
& (1) dibagi dengan nilai perbandingan B \\
dengan A.
\end{tabular}

Tujuan penelitian kedua menentukan strategi pengembangan VCO menggunakan analisis faktor internal dan faktor eksternal selanjutnya dibuatkan matriks IE untukmenentukkan posisi agroindustri VCO dan strategi yang akan diterapkan. Analisis data dimulai dengan mengidentifikasi dan menggolongkan faktor-faktor yang ada di dalam kekuatan dan kelemahan yang merupakan faktor internal, serta peluang dan ancaman yang merupakan faktor eksternal dengan pendekatan analisis kualitatif. Setelah menggolongkan faktor-faktor internal dan eksternal maka dilakukan pembobotan pada masing-masing faktor. Penentuan bobot dilakukan dengan cara mengajukan pertanyaan kepada responden terpilih dengan menggunkan metode Paired comparison (Kinner dan Tailor, 1991). Setiap variabel menggunakan skala 1,2,3 untuk menentukan bobot. Skala yang digunakan untuk menentukan bobot adalah :

$1=$ jika indikator horizontal kurang penting daripada indikator vertikal

$2=$ jika indikator horizontal sama penting dengan indikator vertikal

$3=$ jika indikator horozontal lebih penting daripada indikator vertikal

Setelah mendapatkan nilai terbobot dari faktor internal dan eksternal kemudian dibuatkan matriks IE untuk menentukan posisi agroindustri VCO dan menetapkan strategi yang tepat untuk diterapkan pada agroindustri VCO di Kabupaten Halmahera Barat.

\section{HASIL DAN PEMBAHASAN}

\section{PENENTUAN PRIORITAS JENIS AGROINDUSTRI KELAPA}

Berdasarkan studi literatur dan wawancara dengan pakar diperoleh struktur hirarki yang digunakan dalam penentuan agroindustri kelapa di Kabupaten Halmahera Barat terdiri dari faktor, aktor, tujuan, alternatif dan goal seperti pada Gambar 1. Berdasarkan identifikasi, 6 (enam) faktor penting dalam pengembangan agroindustri diantaranya: 1) bahan baku, 2) SDM, 3) Pasar, 4) Modal, 5) Infrastruktur, dan 6) Teknologi. Sedangkan Aktor yang berperan dalam pengembangan adalah: 1) petani, 2) kelompok tani pengusaha, 3) pemerintah dan 4) akademisi. Sedangkan untuk alternatif diperoleh 7 (Tujuh) jenis produk agroindustri kelapa, yaitu: 1) VCO, 2) kerajinan batok kelapa, 3) minyak goreng, 4) minuman air segar kelapa, 5) kopra, 6) sabut kelapa dan 7) meubel batang kelapa.

Penentuan tingkat pengaruh (bobot) faktor terhadap goal dilakukan dengan alat analisis AHP menggunakan software expertchoice 11 yang dilakukan dari hasil wawancara terhadap 9 (sembilan) pakar yang terpilih. Didapatkan bobot di masing-masing kriteria seperti ditunjukkan dalam Gambar 1. 


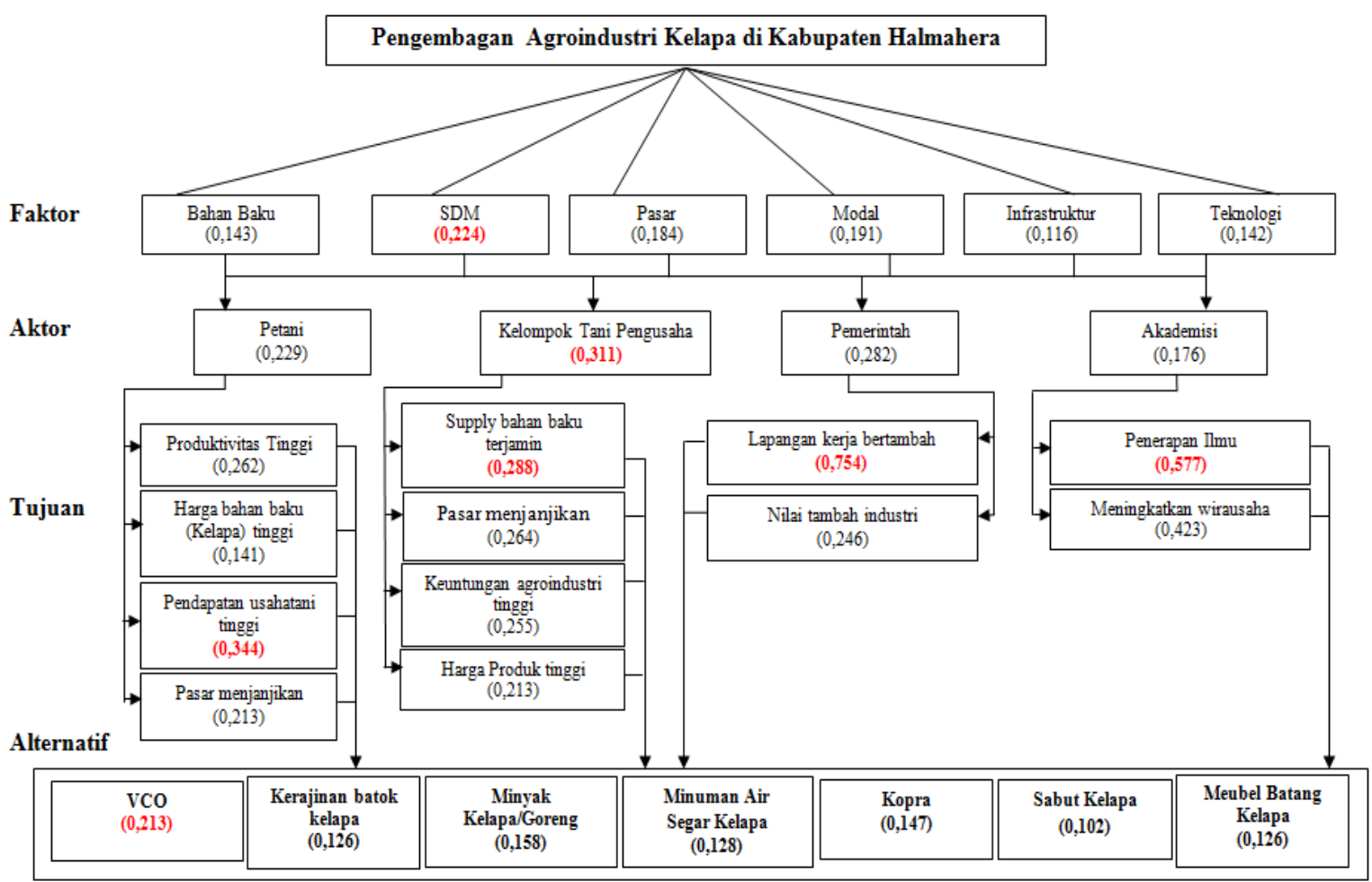

Gambar 1. Struktur Hirarki dan Bobot Prioritas Jenis Agroindustri Kelapa

Hasil analisis menunjukkan bahwa faktor utama yang menjadi penentu keberhasilan pengembangan produk agroindustri kelapa di Kabupaten Halmahera Barat adalah sumber daya manusia (SDM) dengan bobot sebesar 0,224 diikuti oleh faktor modal $(0,191)$, pasar $(0,184)$, bahan baku $(0,143)$, teknologi $(0,142)$ dan infrastruktur diurutan terendah $(0,116)$ seperti pada Gambar 1. Hal ini menunjukkan bahwa napas pemberdayaan industri kelapa di Halmahera Barat adalah dengan meningkatkan produktifitas dan kapabilitas petani itu sendiri. Hasil ini sejalan dengan yang dikatakan Fadhil et al. (2017) bahwa pengembangan SDM merupakan tindakan strategis untuk melahirkan kompetensi dan kualitas pelaku agroindustri dengan daya saing yang tinggi terutama dalam menghadapi persaingan global dan persaingan dalam kawasan Masyarakat Ekonomi ASEAN. Moran dan Brightman (2000) juga berpendapat bahwa keterlibatan SDM sangat menentukan kesuksesan proses perubahan organisasi karena SDM merupakan subjek penting yang akan melaksanakan proses perubahan dan hasil dari proses perubahan yang direncanakan. Pemilihan dan penerapan strategi bisnis yang tepat akan sangat ditentukan oleh kualitas SDM yang berperan penting dalam kegiatan operasional perusahaan, merencanakan dan melaksanakan strategi bisnis yang ditetapkan. Selanjutnya, Jakfar (2014) menegaskan bahwa salah satu upaya mendorong daya saing industri adalah dengan meningkatkan keterampilan SDM. Namun, hasil berbeda ditunjukkan oleh Evalia (2015), di mana SDM mendapat nilai terendah dalam pengolahan produk turunan aren. Hal tersebut dikarenakan pengolahan produk turunan aren tidak membutuhkan SDM yang memiliki keahlian khusus dan teknologi pengolahannya pun tidak rumit.

Selain mempertimbangkan faktor-faktor yang berpengaruh, terdapat pula beberapa aktor yang paling berperan dalam penentuan prioritas produk agroindustri kelapa (Gambar 2). Prioritas pertama dari pelaku yang berperan dalam menentukan keberhasilan pengembangan produk agroindustri kelapa adalah kelompok tani (pengusaha) (31\%) sebagai pelaku industri kelapa. Prioritas kedua adalah pemerintah daerah (Pemerintah Kabupatan Halmahera Barat) (28\%) dalam hal ini adalah Dinas Pertanian dan Perkebunan selaku regulator dan eksekutif pemerintah. Prioritas ketiga adalah petani (23\%) 


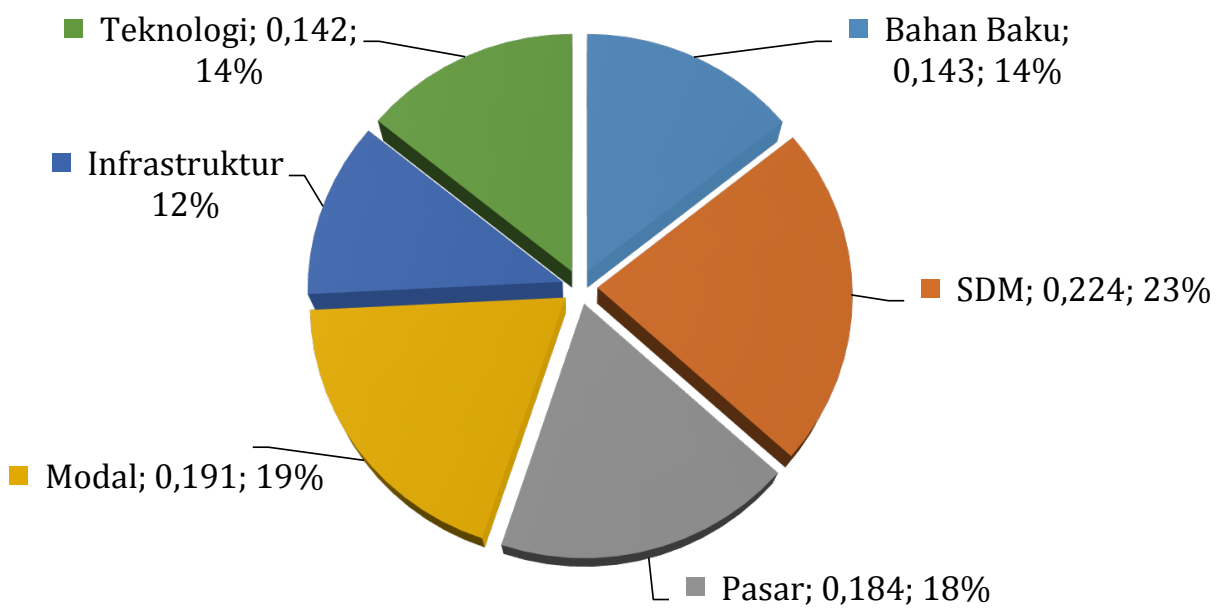

Gambar 2. Eigenvalue Faktor terhadap Agroindustri Kelapa

sebagai penyedia bahan baku, dan yang terakhir adalah akademisi (18\%) selaku pendeseminasi hasil penelitian.

Hal ini menunjukkan SDM memiliki peran penting sehingga dapat menghasilkan daya saing bagi pengembangan agroindustri kelapa. Pada faktor pasar, pengaruh pemerintah $(32 \%)$ dianggap terbesar dalam membuka pasar bagi produk kelapa yang akan dihasilkan oleh pelaku agroindustri. Diikuti oleh aktor lain seperti kelompok tani (30\%), petani (21\%) dan akademisi (16\%). Hal ini menunjukkan perlunya dukungan pemerintah dan akademisi dalam membuka peluang pasar untuk menjaga kualitas produk kelapa yang dihasilkan agar mampu bersaing.

Pada faktor modal, pemerintah dianggap memiliki pengaruh yang sangat kuat (34\%). Sedangkan aktor lain memiliki pengaruh masingmasing kelompok tani pengusaha (28\%), petani (24\%) dan akademisi (13\%). Hal ini menunjukkan dukungan pemerintah dalam menyediakan pin- jaman modal untuk kemajuan agroindustri kelapa. Pada faktor infrastruktur, pemerintah memiliki peran yang sangat penting (42\%) sedangkan sisanya dimiliki oleh aktor lain. Sedangkan untuk faktor teknologi, pemerintah merupakan aktor yang paling berperan (34\%) dalam menyediakan teknologi agroindustri kelapa.

Tingkat kepentingan relatif setiap aktor terhadap keberhasilan pengembangan agroindustri kelapa diperoleh melalui perkalian antara eigenvalue masing-masing aktor terhadap setiap faktor dengan eigenvalue faktor terhadap agroindustri kelapa. Eigenvalue yang dihasilkan menunjukkan aktor kelompok tani memiliki pengaruh yang sangat besar (31\%) terhadap keberhasilan pengembangan agroindustri kelapa. Selanjutnya diikuti oleh aktor pemerintah (28\%), petani (23\%) dan akademisi (18\%).

Analisis penentuan jenis agroindustri dilakukan dengan membandingkan alternatif jenis agroindustri kelapa terhadap tujuan pengembangan agroindustri. Dari penilaian tersebut,

Tabel 3. Aktor yang Berperan dalam Pengembangan Agroindustri Kelapa di Kabupaten Halmahera Barat

\begin{tabular}{|c|c|c|c|c|c|c|c|}
\hline \multirow[t]{2}{*}{ Aktor } & $\begin{array}{c}\text { Bahan } \\
\text { Baku }\end{array}$ & $\begin{array}{c}\text { Sumber } \\
\text { Daya } \\
\text { Manausia }\end{array}$ & Pasar & Modal & Infrastruktur & Teknologi & \multirow[t]{2}{*}{$\begin{array}{l}\text { Total } \\
\text { Bobot } \\
\text { Aktor }\end{array}$} \\
\hline & 0,143 & 0,224 & 0.184 & 0,191 & 0,116 & 0,142 & \\
\hline Petani & 0,371 & 0,207 & 0,210 & 0,238 & 0,189 & 0,170 & 0,230 \\
\hline Kelompok Tani Pengusaha & 0,341 & 0,423 & 0,305 & 0,288 & 0,221 & 0,223 & 0,312 \\
\hline Pemerintah & 0,144 & 0,186 & 0,316 & 0,342 & 0,420 & 0,337 & 0,282 \\
\hline Akademisi & 0,144 & 0,184 & 0,169 & 0,133 & 0,171 & 0,269 & 0,176 \\
\hline
\end{tabular}


Tabel 4. Eigenvalue Jenis Agroindustri terhadap Setiap Tujuan

\begin{tabular}{ccccccccc}
\hline & & \multicolumn{7}{c}{ Jenis Agroindustri Kelapa } \\
\hline No & Ket & VCO & $\begin{array}{c}\text { Kerajinan } \\
\text { Batok Kelapa }\end{array}$ & $\begin{array}{c}\text { Minyak } \\
\text { goreng }\end{array}$ & $\begin{array}{c}\text { Minum Air } \\
\text { Segar }\end{array}$ & Kopra & $\begin{array}{c}\text { Sabut } \\
\text { Kelapa }\end{array}$ & $\begin{array}{c}\text { Meubel } \\
\text { Batang Kelapa }\end{array}$ \\
\hline $\mathbf{1}$ & $\mathbf{0 , 2 6 2}$ & 0,286 & 0,085 & 0,174 & 0,098 & 0,167 & 0,094 & 0,094 \\
$\mathbf{2}$ & $\mathbf{0 , 1 4 1}$ & 0,234 & 0,095 & 0,165 & 0,111 & 0,195 & 0,091 & 0,109 \\
$\mathbf{3}$ & $\mathbf{0 , 3 4 4}$ & 0,236 & 0,096 & 0,173 & 0,102 & 0,195 & 0,083 & 0,115 \\
$\mathbf{4}$ & $\mathbf{0 , 2 5 3}$ & 0,211 & 0,100 & 0,159 & 0,144 & 0,168 & 0,097 & 0,121 \\
$\mathbf{5}$ & $\mathbf{0 , 2 5 7}$ & 0,193 & 0,122 & 0,179 & 0,119 & 0,208 & 0,086 & 0,092 \\
$\mathbf{6}$ & $\mathbf{0 , 2 8 3}$ & 0,247 & 0,107 & 0,143 & 0,113 & 0,221 & 0,082 \\
$\mathbf{7}$ & $\mathbf{0 , 2 5 6}$ & 0,266 & 0,089 & 0,176 & 0,114 & 0,161 & 0,081 & 0,087 \\
$\mathbf{8}$ & $\mathbf{0 , 2 0 4}$ & 0,233 & 0,090 & 0,161 & 0,122 & 0,168 & 0,101 & 0,114 \\
$\mathbf{9}$ & $\mathbf{0 , 7 5 4}$ & 0,181 & 0,154 & 0,160 & 0,128 & 0,123 & 0,104 & 0,125 \\
$\mathbf{1 0}$ & $\mathbf{0 , 2 4 6}$ & 0,218 & 0,146 & 0,154 & 0,135 & 0,125 & 0,104 & 0,118 \\
$\mathbf{1 1}$ & $\mathbf{0 , 5 7 7}$ & 0,247 & 0,137 & 0,122 & 0,133 & 0,067 & 0,143 \\
$\mathbf{1 2}$ & $\mathbf{0 , 4 2 3}$ & 0,151 & 0,161 & 0,145 & 0,183 & 0,089 & 0,127 \\
\hline
\end{tabular}

Keterangan :

1. Produktivitas tinggi 7. Keuntungan agroindustri tinggi

2. Harga bahan baku tinggi

3. Pendapatan usahatani tinggi

4. Pasar menjanjikan

5. Supply bahan baku terjamin

6. Pasar menjanjikan

\author{
8. Harga produk tinggi \\ 9. Lapangan kerja bertambah \\ 10. Nilai tambah agroindustri \\ 11. Penerapan ilmu \\ 12. Meningkatkan wirausaha
}

didapatkan bahwa alternatif jenis produk agroindustri yang menjadi peluang utama yang dapat dikembangkan dan memiliki nilai tambah yang tinggi adalah VCO (Tabel 4). Hal ini dikarenakan produk tersebut memiliki peluang pasar yang besar dan harga jual yang tinggi dibandingkan dengan agroindustri kelapa lain yang diproduksi (Mannekote dan Kailas, 2013). Selain itu, VCO juga memiliki manfaat yang sangat baik bagi kesehatan (Manikantan et al., 2015). Menurut Yeap et al. (2014) VCO dapat mengobati stres dibanding obat kimia. Hal ini dikarenakan faktor asam lemak rantai menengah yang ditemukan dalam minyak kelapa, kaya lemak jenuh, dan antioksidan hadir dalam kelas yang lebih tinggi.

Jika investasi agroindustri kelapa difokuskan pada kemampuan industri untuk memberi nilai tambah dan keuntungan yang besar bagi petani, maka produksi VCO merupakan pilihan yang tepat. Pengembangan industri ini dapat ditingkatkan dengan, perkembangan teknologi terbaru pengolahan minyak kelapa murni skala kecil, dikombinasikan dengan bukti tingginya tingkat permintaan konsumen di pasar lokal dan domestik, bisa menghemat biaya produksi. Lebih jauh lagi, pengembangan produk ini menawarkan cara yang menjanjikan untuk meningkatkan konsumsi domestik produk yang diproduksi secara lokal, yang seharusnya membantu men- stabilkan pendapatan petani. (Henderson et al., 2006).

\section{STRATEGI PENGEMBANGAN AGROINDUSTRI VCO DI KABUPATEN HALMAHERA BARAT}

Proses perumusan strategi pengembangan agroindustri Virgin Coconut Oil dilakukan dengan melihat dan menganalisis lingkungan agroindustri VCO. Analisis dilakukan dengan melihat faktor internal dan eksternal yang berpengaruh dalam pengembangan agroindustri VCO. Hasil analisis faktor-faktor kunci internal dan eksternal pada agroindustri VCO di Kabupaten Halmahera Barat yang didapatkan melalui wawancara serta disesuaikan dengan kondisi agroindustri VCO. Berdasarkan hasil wawancara untuk faktor internal diperoleh 8 faktor kekuatan dan 8 faktor kelemahan. Sedangkan faktor eksternal diperoleh 10 faktor yang terdiri dari 6 faktor peluang dan 4 faktor ancaman. Masing-masing faktor berserta skornya dapat dilihat pada Tabel 5 dan 6.

Pada Tabel 5 dapat dilihat nilai terbobot untuk faktor internal sebesar 3,27, hal ini menunjukkan bahwa agroindustri VCO di Kabupaten Halmahera Barat berada pada posisi kuat dalam memanfaatkan kekuatan yang dimiliki dan mampu mengatasi kelemahan yang ada. Kekuatan yang dimiliki yaitu ketersediaan bahan baku dengan nilai 0,79 sedangkan kelemahan utama yang 
Tabel 5. Faktor Internal Agroindustri VCO

\begin{tabular}{|c|c|c|c|}
\hline Faktor Internal & Bobot & Rating & $\begin{array}{c}\text { Skor } \\
\text { (bobot x rating) }\end{array}$ \\
\hline \multicolumn{4}{|l|}{ Kekuatan } \\
\hline A. Ketersediaan bahan baku & 0,20 & 4,00 & 0,79 \\
\hline B. Bahan baku bekualitas & 0,07 & 4,00 & 0,27 \\
\hline C. Motivasi dalam berusaha & 0,17 & 3,80 & 0,64 \\
\hline D. Harga bahan bakuterjangkau & 0,11 & 3,40 & 0,38 \\
\hline E. Produk bebas dari bahan pengawet & 0,09 & 3,80 & 0,33 \\
\hline F. Lokasi agroindustri strategis & 0,07 & 3,40 & 0,24 \\
\hline G. Tenaga kerja lokal tersedia & 0,05 & 3,60 & 0,18 \\
\hline H. Memiliki PIRT & 0,04 & 3,60 & 0,13 \\
\hline \multicolumn{4}{|l|}{ Kelemahan } \\
\hline I. Keterbatasan modal & 0,04 & 1,00 & 0,04 \\
\hline J. Sistem manajemen belum optimal & 0,05 & 1,40 & 0,07 \\
\hline K. Kemitraan usaha kecil & 0,02 & 1,80 & 0,03 \\
\hline L. Produk belum terdaftar di BPOM & 0,03 & 1,40 & 0,04 \\
\hline M. Pencatatan keuangan masih Sederhana & 0,02 & 1,80 & 0,03 \\
\hline N. Menggunakan kemasan sederhana (botol plastik) & 0,04 & 1,60 & 0,06 \\
\hline 0. Waktu pengerjaan (produksi) relatif panjang & 0,01 & 2,00 & 0,03 \\
\hline P. Kemampuan menembus pasar potensial & 0,01 & 1,00 & 0,01 \\
\hline Total & 1,00 & 41,60 & 3,27 \\
\hline
\end{tabular}

dimiliki adalah kemampuan menembus pasar potensial dengan nilai 0,0 .

Tabel 6 menunjukkan nilai terbobot untuk faktor eksternal sebesar 3,65. Nilai ini menunjukkan kemampuan agroindustri VCO tergolong tinggi dalam memanfaatkan peluang yang ada dalam mengatasi ancaman. Peluang utama yang dimiliki adalah bahan baku yang mudah didapatkan dengan nilai sebesar 1,20, sedangkan ancaman utama yang dihadapi adalah saingan dengan daerah lain yang lebih dahulu mengembangkan VCO dengan nilai 0,03 .
Berdasarkan Tabel 5 dan 6 maka disusunlah sebuah analisis yang menggabungkan unsur internal dan eksternal dalam bentuk matriks internal-eksternal (IE Matrix).

Pemetaan pada matriks IE dapat dilihat bahwa sumbu- $x$ matrix IE nilai total matriks IFE adalah 3,27 sedangkan pada sumbu- $y$ matriks IE nilai total EFE adalah 3,65. Hasil dari matriks IE menunjukkan bahwa agroindustri VCO berada pada sel 1. Sel 1 dapat digambarkan sebagai tumbuh dan membangun. Pada posisi ini strategi yang dapat digunakan menurut David (2012), adalah strategi intensif (penetrasi pasar, pengem-

Tabel 6. Faktor Eksternal Agroindustri VCO

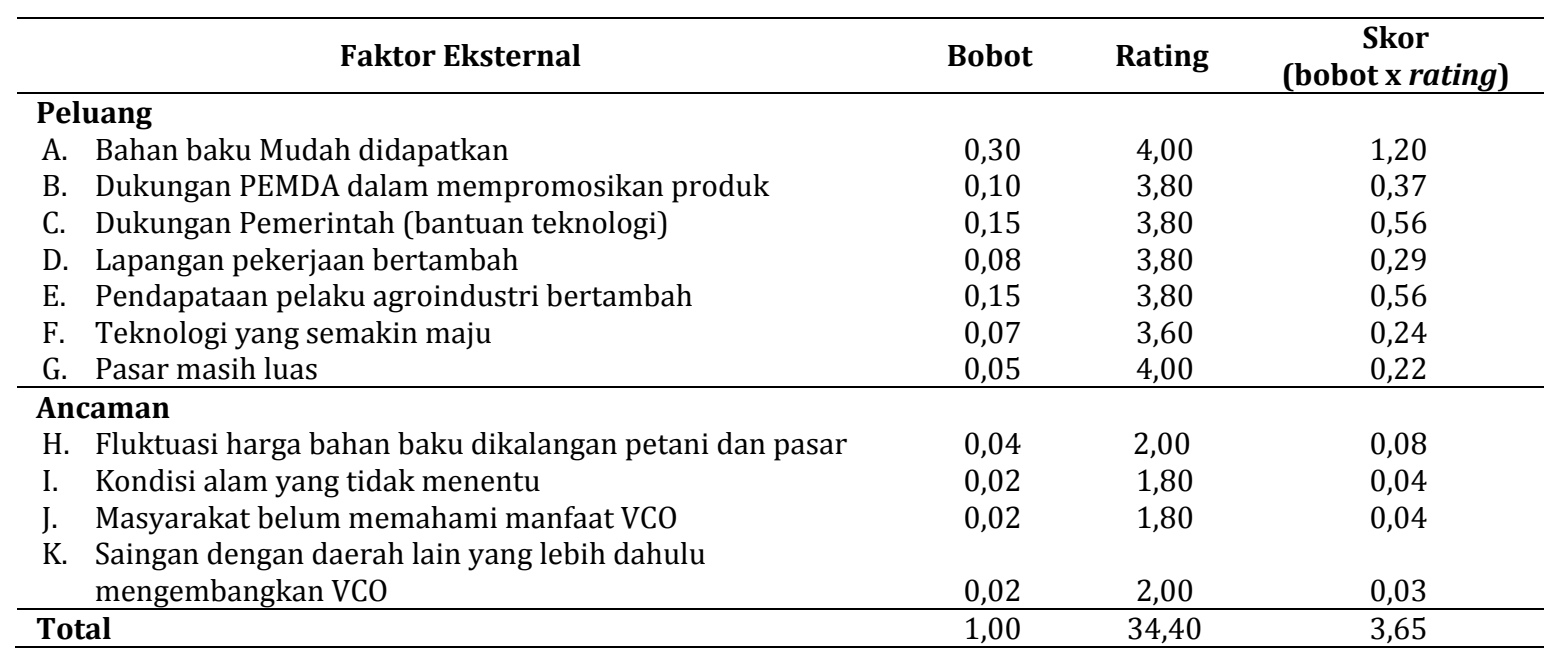




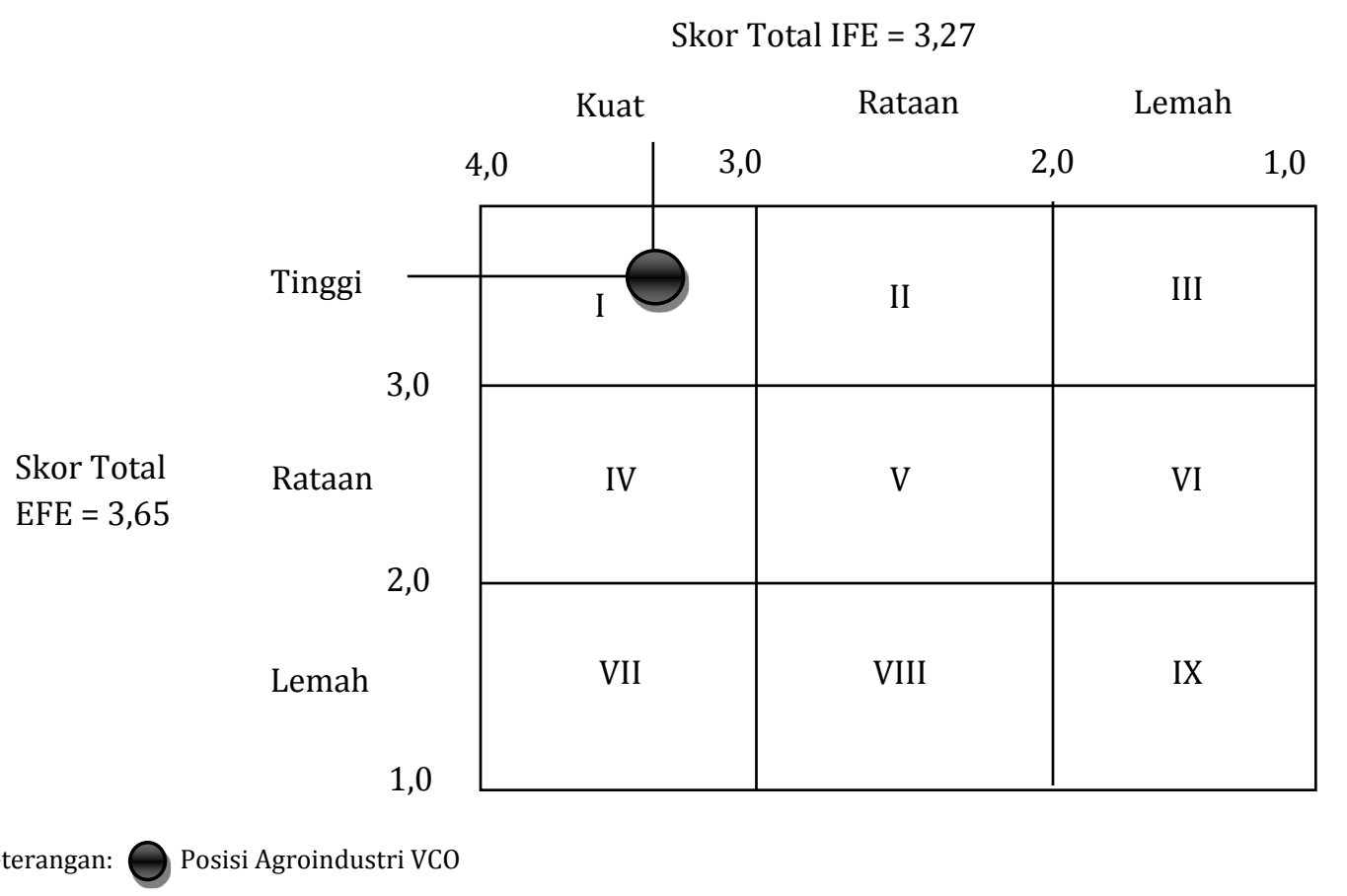

Gambar 3. Matriks Internal-Eksternal Agroindustri VCO di Kabupaten Halmahera Barat

bangan pasar dan pengembangan produk) dan strategi integratif.

Pengembangan pasar merupakan salah satu bagian dari kemungkinan pertumbuhan intensif, pada kemungkinan ini pertumbuhan yang dicapai tanpa mengubah sistem pemasaran perusahaan. Pengembangan pasar yang perlu dilakukan melalui dua cara, diantaranya: (1) secara geografis, perusahaan membuka pasar tambahan, baik melalui perluasan secara regional dan internasional, (2) perusahan berusaha menarik pangsa pasar yang lain dengan jalan mengembangkan versi produk, misalnya produk ditawarkan dengan kemasan yang lebih menarik, cara pelayanan yang lebih istimewa, atau dengan cara memasuki jalur yang lain, atau dapat dilakukan dengan memasang iklan pada media yang lain. Strategi pengembangan produk dilakukan untuk menawarkan produk baru atau memodifikasi produk ke segmen pasar yang sekarang. Strategi ini dilakukan agar penjualan dapat meningkat dan keuntungan perusahaan juga meningkat.

Strategi intensif yaitu penetrasian pasar, pengembangan pasar dan pengembangan produk yang diterapkan pada agroindustri VCO di Kabupaten Halmahera Barat adalah meningkatkan penjualan produk yang telah ada ke pasar yang sudah ada juga. Penetrasi pasar ini dapat diimplementasikan dengan memodifikasi produk, meningkatkan kualitas dan mempromosikan cara baru untuk menggunakan produk mengingat VCO merupakan produk yang memiliki manfaat baik itu untuk kesehatan maupun kecantikan. Selama ini penjualan VCO lebih banyak dipasarkan di dalam wilayah Halmahera Barat, Kota Ternate, bahkan dijual pada saat event pariwisata seperti Festival Teluk Jailolo dan beberapa event kedaerahan lainnya. Selain itu, produk VCO juga dijual di salah satu Rumah Sakit di kabupaten Halmahera Utara maka perlu melakukan promosi dengan menggunakan teknologi informasi seperti internet agar produk dapat menembus pasar luar negeri seperti Malaysia, Filipina dan negaranegara yang sudah mengenal VCO. Meningkatkan kualitas produk tidak hanya dalam hal khasiat dan komposisi melainkan memperbaharui kemasan agar lebih menarik. Kemasan yang lebih menarik akan menarik perhatian konsumen.

\section{SIMPULAN DAN SARAN}

\section{SIMPULAN}

Berdasarkan hasil dan pembahasan, dapat disimpulkan bahwa:

1. Agroindustri virgin coconut oil (VCO) memiliki prioritas tertinggi dalam dalam pengem- 
bangan agroindustri kelapa di Kabupaten Halmahera Barat. Dengan pengembangan agroindustri ini maka pelaku usaha akan mendapat nilai tambah dari usaha yang dijalankan yang pada akhirnnya akan meningkatkan pendapatan. Selain itu, pengembangan agroindustri VCO akan membuka lapangan kerja baru di pedesaan.

2. Strategi yang diterapkan pada VCO di Kabupaten Halmahera Barat adalah Strategi intensif: penetrasian pasar, pengembangan pasar dan pengembangan produk. Sedangkan strategi interaktif: integrasi ke depan/hulu, integrasi ke belakang/hilir dan integrasi horizontal

\section{SARAN}

1. Untuk lebih berkembangnya agroindustri kelapa maka Pemerintah Daerah Kabupaten Halmahera Barat harus menjadi pendorong dengan membentuk klaster agroindustri VCO tingkat kelompok tani yang disesuaikan dengan ketersediaan pasokan bahan baku dan membangun jaringan kerja sama pemasaran VCO. Selanjutnya, promosi agroindustri komoditas unggulan Kabupaten Halmahera Barat kepada para investor baik nasional maupun luar negeri serta menyediakan informasi pasar produk olahan agroindustri kelapa.

2. Agar kegiatan agroindustri kelapa dapat berjalan dengan baik diperlukan kerja sama semua stakeholder terkait agar agroindustri dapat tumbuh dan berkembang dengan baik mulai dari pengadaan bahan baku sampai pengadaan teknologi, infrastruktur, informasi pasar dalam dan luar negeri.

\section{DAFTAR PUSTAKA}

[BPS] Badan Pusat Statistik Kabupaten Halmahera Barat 2016.Halmahera Barat dalam Angka. Halmahera Barat (ID): BPS Kabupaten Halmahera Barat.

Budianto JD. Allolerung. 2003. Kelembagaan perkelapaan. Prosiding Konferensi Nasional Kelapa V. Tembilahan, 22-24 Oktober 2002. Pusat Penelitian dan Pengembangan Perkebunan, Bogor (ID).
Budiarto. 2010. Pembangunan ekonomi perdesaan melalui agroindustri: Penentuan prioritas pengembangan jenis agroindustri kelapa di Kabupaten Kulonprogo. J. SEPA 7 (1): 6-14.

David FR. 2012. Strategic management: a competitive advantage approach, concepts and cases (14th Edition). New Jersey: Prentice Hall.

Evalia NA. 2015. Strategi pengembangan agroindustri gula semut aren. J. Manajemen \& Agribisnis. 12(1):57-67.

Fadhil R, Maarif MS, Bantacut T, Hermawan A.2017.Model strategi pengembangan sumber daya manusia agroindustri kopi gayo dalam menghadapi masyarakat ekonomi ASEAN.J. Manajemen Teknologi 16 (2): 141156.

Henderson BB, Henry L, MacAulay G. 2006. Investment and change in the coconut industry of North Sulawesi: an equilibrium displacement analysis. Australian agricultural and resource economics society. 50th annual conference;8-10 February 2006; Sydney, NSW (AUS).

Jakfar AA. 2014. Mendorong daya saing industri di Madura melalui pendekatan klaster industri. J.Agrointek. 8(2):75-84.

Krishnakumar V, Kalavathi S, Thomas RJ, Thomas GV. 2013. Diversification of coconut based farming system through community based organizations for income generation and sustaining productivity. J. Plantation Crops. 41(3): 271-276.

Kuncoro M. 2012. Ekonomika Pembangunan. Jakarta: Penerbit Erlangga.

Lay A, Pasang PM. 2012. Strategi dan Implementasi Pengembangan produk kelapa masa depan. J. Perspektif. 11 (1): 01-22.

Manikantan MR, Ambrose RPK, Alavi S. 2015. Flow-specifc physical properties of coconut flours.J. International Agrophysics. 29:1-7. doi: 10.1515/intag-2015-000.

Mannekote JK, Kailas SV. 2013. Value added products from Coconut oil. J. Indian Coconut [Internet]. [diunduh: 20 Agustus 2018]. Tersedia 
pada:https://www.researchgate.net/profile /Jagadeesh_Kumar_Mannekote/publication/ 237803592_Value_added_products_from_Co conut_oil/links/0c96051bbf3e37fea100000 $0 /$ Value-added-products-fromCoconutoil.pdf?origin=publication_detail.

Marimin, Maghfiroh. 2010. Aplikasi tekhnik pengambilan keputusan dalam manajemen rantai pasok. IPB Press. Bogor (ID).

Moran, Brightman. 2000. Leading organizational change. J. Workplace learning: Employee counselling today. 12 (2): 66-74.

Muyengi ZE, Msuya E, Lazaro E. 2015. Assessment of factors affecting coconut production in Tanzania.J. Agricultural Economics and Development. 4(6): 083-094.

Pathiraja PMEK, Griffith GR, Farquharson RJ, Faggian R. 2015. The Sri Lanka coconut industry: current status and future prospects in a changing climate. Australasian agribusiness perspectives.

Saaty TL. 1990. How to make a decision: The analytic hierarchy process. J. European of Operation Research. 48:9-26.

Suharto JC. 2018. Potentials for increasing farmers' income and enhancing competitiveness of the coconut industry through alternative uses [Internet]. [diunduh: 18 Agustus 2018]. Tersedia pada: https://www.bioversityinternational.org/fil eadmin/bioversity/publications/Web_versi on/198/ch03.html.

Ulrich KT, Eppinger SD. 2001. Perancangan dan pengembangan produk. Salemba Teknika, Jakarta (ID).

Yeap SW, Beh BK, Ali NM, Yusof HM, Ho WY, Koh SP, Altheen. 2014. Antistrees and antioxidant effects of virgin coconut oil in vivo [Internet]. [diunduh 8 Agustus 2018]. Tersedia pada: https://doi.org/10.3892/etm.214 